\title{
Preliminary Study on Bio Fortification of Fermented Cereals
}

\author{
Olusola Ladokun*, Sarah Oni, Oluwatoyin Odegbile \\ Department of Biochemistry, Faculty of Sciences, Lead City University, Ibadan, Nigeria
}

Email address:

solaJP@gmail.com (O. Ladokun)

${ }^{*}$ Corresponding author

\section{To cite this article:}

Olusola Ladokun, Sarah Oni, Oluwatoyin Odegbile. Preliminary Study on Bio Fortification of Fermented Cereals. International Journal of Nutrition and Food Sciences. Vol. 6, No. 5, 2017, pp. 199-202. doi: 10.11648/j.ijnfs.20170605.13

Received: February 28, 2017; Accepted: March 25, 2017; Published: August 17, 2017

\begin{abstract}
Food fortification is the process of increasing the nutritional value of plant foods. In this study, fermented products from maize, millet and sorghum were fortified with soy bean and ginger. The samples were assessed for nutritional improvement using standard protocol. There were marked increase in the amount of ash, protein and crude fibre content but a decrease in carbohydrate content in all the fortified cereal samples. The ash, protein, crude fibre and carbohydrate content of the fortified samples were as follows: Maize (\% dry weight; $9.46 \pm 0.93,42.10 \pm 0.57,4.95 \pm 0.14$ and $36.01 \pm 0.04$ respectively. Millet (\% dry weight); $8.95 \pm 5.16,42.00 \pm 0.28,5.67 \pm 0.11$ and $16.00 \pm 0.46$ respectively and sorghum (\% dry weight); 28.98 $\pm 5.16,42.00 \pm 0.28,5.65 \pm 0.11$ and $16.00 \pm 0.16$ respectively. Fortification of cereal with soybean and ginger increases protein, ash and fibre content in the cereal. Consequently, the carbohydrate and fat were reduced in the fortified samples.
\end{abstract}

Keywords: Fortification, Cereal, Soy Bean, Ginger

\section{Introduction}

Biofortification is the process of increasing the concentration and bioavailability of the nutritional content of the edible part of the plant foods to the levels that consistently exceed the average content observed [1]. Food fortification has proven to be a very effective intervention for the prevention of nutritional deficiencies [2].

Fermentation is the oldest known form of food biotechnology, which has been practiced for thousands of years. It is a potent method for preserving foods and it plays an important role in food technology. In fermentation processes, natural micro-organisms are employed in the preparation and preservation of different types of food [3]. Fermented food products include; alcohols, breads, beverages, vinegar, pickled sausages, cheeses, and yogurts and they are of great significance because they provide and preserve vast quantities of nutritious foods to enrich the human diet [4]. The term cereal is a derivative from Latin word 'cerealis' meaning 'grain' which is botanically a type of fruit called caryopsis, composed of the endosperm, germ and bran which usually have long, thin stalks such as maize, sorghum and millet whose starchy grains are used as food [5]. Cereals are the edible seeds or grains of the grass family, Gramineae. A number of cereals are grown in different countries, including rye, oats, barley, maize, triticale, millet and sorghum. Cereals have a long history of use by humans. Cereals are staple foods, and are important sources of nutrients in both developed and developing countries. Cereals and cereal products are an important source of energy, carbohydrate, protein and fibre, as well as containing a range of micronutrients such as vitamin $\mathrm{E}$, some of the $\mathrm{B}$ vitamins, magnesium and zinc. In the UK, because of the mandatory fortification of some cereal products (e.g. white flour and therefore white bread) and the voluntary fortification of others (e.g. breakfast cereals), cereals also contribute significant amounts of calcium and iron. Cereals and cereal products may also contain a range of bioactive substances and there is growing interest in the potential health benefits these substances may provide. [6] The chemical composition of cereal grains is characterized by the high content of carbohydrates. Available carbohydrates mainly starch deposited in the endosperm, amount to 56-74\% and fiber, mainly located in the bran, 2-13\%. The second important group of constituents is the proteins which fall within an average range of about $8-11 \%$ [7]. Cereals are 
particularly important substrates for fermented foods in all parts of the world and are staples in the Indian subcontinent, in Asia and in Africa [3].

'Ogi' is a fermented porridge or gruel made from cereals in West-Africa. It could be made from maize (Zea mays), sorghum (Sorghum bicolor) or millet (Pennisetum glancum) with characteristic flavor and sour taste. Its fermentation involves Lactobacillus spp and various yeasts including Saccharomyces cerivisiae [8].

Studies have shown that some spices can increase the shelf life of 'Ogi'. Ginger is one of the widely consumed aromatic spices used as a preservative agent [9] and, soybean which is rich in proteins, fibre, calcium and magnesium were used to fortify the cereal samples in the present study. The aim of this work is to assess the proximate compositions of the cereal and fortified cereal samples and also to compare their nutritive value.

\section{Materials and Methods}

\subsection{Sample Source}

The samples used for this study were purchased from Orita Market, Challenge, Ibadan, Nigeria.

\subsection{Sample Preparation}

$1000 \mathrm{~g}$ each of maize, millet and sorghum were used in this study. Each sample was divided into 2 equal portions and soaked in clean water for 72 hours. A portion of each sample was fortified with $500 \mathrm{~g}$ of soybeans and $250 \mathrm{~g}$ of peeled ginger while the other portion was not fortified. Each portion was milled and sieved separately.

\subsection{Proximate Analysis}

Proximate compositions of the powered samples were determined using the standard method of AOAC (2000) [10].

\subsection{Sensory Evaluation}

A questionnaire was designed for the sensory evaluation. The sensory evaluation was done using random sampling.

\subsection{Statistical Analysis}

The results obtained were subjected to analysis of Student t-test to compare each parameter analysed between samples and their fortified samples. Comparisons were carried out by Statistical Programs for Social Sciences. (SPSS, 1992).

\section{Results}

\subsection{Proximate Analysis of Sorghum Samples}

There were significant increase in ash, crude protein, and crude fibre contents of fortified sorghum when compared with sorghum alone. However, significant decrease was observed in fat and carbohydrate content.

Table 1. Below indicates the proximate analysis of sorghum and fortified sorghum.

\begin{tabular}{lllllll}
\hline Sample & Ash (\%) & Moisture (\%) & Crude Protein (\%) & Crude Fibre (\%) & Fat (\%) & $\begin{array}{l}\text { Carbohydrate } \\
(\%)\end{array}$ \\
\hline Sorghum & $7.02 \pm 0.19$ & $1.57 \pm 0.07$ & $21.85 \pm 0.49$ & $1.70 \pm 0.35$ & $\begin{array}{l}\text { Energy Value } \\
(\mathbf{k J} / \mathbf{1 0 0 g})\end{array}$ \\
Sorghum + SG & $16.88 \pm 1.53 *$ & $1.42 \pm 0.02$ & $61.85 \pm 1.20 *$ & $3.25 \pm 0.21 *$ & $5.80 \pm 0.05$ & $60.59 \pm 0.09$ \\
\hline
\end{tabular}

Values are presented in mean \pm standard deviations. $\mathrm{SG}=$ soybeans and ginger.

*Fortified sample is significantly different when compared with main sample at $\mathrm{P}<0.05$.

\subsection{Proximate Analysis of Millet Samples}

Table 2. Indicates the proximate analysis of millet and fortified millet.

\begin{tabular}{lllllll}
\hline Sample & Ash (\%) & Moisture (\%) & Crude Protein (\%) & Crude Fiber (\%) & Fat (\%) & $\begin{array}{l}\text { Carbohydrate } \\
\text { (\%) }\end{array}$ \\
\hline Millet & $11.25 \pm 0.33$ & $1.71 \pm 0.15$ & $21.08 \pm 0.11$ & $1.95 \pm 0.19$ & $6.46 \pm 0.16$ & $57.55 \pm 0.12$ \\
Millet + SG & $28.98 \pm 5.16^{*}$ & $1.04 \pm 0.69$ & $41.80 \pm 0.78^{*}$ & $5.67 \pm 0.11^{*}$ & $5.75 \pm 0.07$ & $16.0 \pm 0.47 *$ \\
\hline
\end{tabular}

Values are presented in mean \pm standard deviations. $\mathrm{SG}=$ soybeans and ginger

*Fortified sample is significantly different when compared with main sample at $\mathrm{P}<0.05$

There were significant increase $(\mathrm{p}<0.05)$ in Ash, crude protein, and crude fibre contents of fortified millet compared with millet alone. But, carbohydrate has significant reduction in fortified millet.

\subsection{Proximate Analysis of Maize Samples}

Table 3. Below indicates the proximate analysis of maize and fortified maize.

\begin{tabular}{|c|c|c|c|c|c|c|c|}
\hline Sample & Ash (\%) & Moisture (\%) & Crude Protein (\%) & Crude Fiber (\%) & Fat (\%) & Carbohydrate (\%) & $\begin{array}{l}\text { Energy Value } \\
(\mathrm{kJ} / 100 \mathrm{~g})\end{array}$ \\
\hline Maize & $5.43 \pm 0.38$ & $2.17 \pm 0.23$ & $13.25 \pm 0.35$ & $1.99 \pm 0.23$ & $5.45 \pm 0.30$ & $71.71 \pm 1.32$ & $16.46 \pm 0.14$ \\
\hline Maize + SG & $9.46 \pm 0.93 *$ & $2.17 \pm 0.10$ & $42.10 \pm 0.56^{*}$ & $4.95 \pm 0.14^{*}$ & $5.31 \pm 0.08$ & $36.01 \pm 0.04 *$ & $15.24 \pm 1.23$ \\
\hline
\end{tabular}

Values are presented in mean \pm standard deviations. $\mathrm{SG}=$ soybeans and ginger

*Fortified sample is significantly different when compared with main sample at $\mathrm{P}<0.05$ 
There were significant increase $(\mathrm{p}<0.05)$ in Ash, crude protein, and crude fibre contents of fortified maize compared with maize alone. But significant reduction was observed in carbohydrate content.

\subsection{Sensory Evaluation of Fortified Cereals (Millet, Maize and Sorghum)}

Table 4. Indicates sensory evaluation of fortified cereals (millet, maize and sorghum).

\begin{tabular}{llllll}
\hline Sample & Taste (\%) & Appearance (\%) & Odour (\%) & Texture (\%) & Overall Acceptability (\%) \\
\hline Wet Fortified millet & $80.00 \pm 3.21$ & $63.33 \pm 0.50$ & $73.33 \pm 3.40$ & $73.33 \pm 2.03$ & $72.50 \pm 5.03$ \\
Wet fortified maize & $76.60 \pm 1.05$ & $63.30 \pm 2.04$ & $73.00 \pm 2.03$ & $70.00 \pm 2.03$ & $70.73 \pm 3.20$ \\
Wet fortified sorghum & $70.00 \pm 2.04$ & $76.67 \pm 3.05$ & $70.00 \pm 3.04$ & $80.00 \pm 3.40$ & $74.17 \pm 4.30$ \\
\hline
\end{tabular}

The chemical composition of unfortified cereal grains is characterized by the high content of carbohydrates [7]. This study shows that fortification of maize, millet and sorghum with soybeans (Glycine max) and spice ginger (Zingiber officinales) had a significant effect on their crude ash, crude protein, crude fibre, moisture, energy value and carbohydrate contents. There was a significant increase in the quantity of crude protein, crude ash and crude fibre while there was a decrease in moisture, carbohydrates, fats and energy value.

Cereals fortified with soybean and ginger had high protein content. Proteins play an important role in growth (especially for children, teens, and pregnant women), tissue repair and provide energy when carbohydrate is not available in the body. Mixing soybeans, which has been reported to have high protein content [11] and ginger contains protein [12] may cause overall increase in the amount of crude protein in the fortified cereal samples which is useful in the body.

Food high in calorific intake may increase the risk of hypertension and cardiovascular complications [13] but meals made from fortified cereals have low amounts of calories which makes it suitable for those suffering from hypertension and cardiovascular complications. However, consuming food with significantly low amount of calories may also result in under nutrition and weight loss. It is expected that the fortified sample will have significant increase in crude fat since soybeans have high fat content [14]. Fortified samples have a decrease in the quantity of calories but an increase in crude protein, crude fibre and mineral ash which will combat with under nutrition and weight loss.

In this study, the fat content of the cereals and fortified cereals were observed to be low. Food with high fat contents increases the risk of cardiovascular diseases [13]. Consuming fermented cereal fortified with soybean and ginger may be of advantage in patients with metabolic disorder and cardiovascular diseases.

Cereals fortified with soy bean and ginger have high crude fibre content. Crude fibre play a crucial role in preventing constipation, controls sugar level, helps lower cholesterol and controls bowel movement. Adding ginger, which has been reported to have higher crude fibre content than soybean may be the cause of overall increase in the amount of crude fibre in the fortified cereal samples [15]. Adding soy beans and ginger to the cereals increased their ash content, an increased level of crude ash signifies an increase in the quantity of mineral content of the fortified cereals, although during the course of this study we were unable to quantify the mineral content but an increase in the quantity of crude ash in the fortified samples showed that more minerals were present in the fortified cereal samples than the unfortified samples.

The sensory evaluation showed that the overall acceptability based on the taste, color, odor and the appearance of the fortified cereals scored above $70 \%$ indicating that it was good for consumption. Fortified cereals are relatively cheap and good sources of all food nutrients especially protein, minerals and crude fibre which is vital for growth and development, It could be introduced in the meals of children and women in War-torn areas in which animal proteins and fruits are not easily accessible. Fortified cereal could also be introduced into the meals of weaned babies, lactating mothers, convalescing patients and the elderly due to its good balance in nutrient level reducing the ones that may be hazardous to health while increasing the ones that are beneficial to health.

\section{Conclusion}

Fortification of cereals samples shows a better yield in crude fibre, crude protein, and minerals which is represented by ash contents in the samples. We were unable to assess the mineral and vitamins contents in the fortified samples in relation with the cereal samples. We therefore recommend that further study should be conducted on minerals as well as vitamin contents of these fortified samples.

\section{References}

[1] White P. J and Broadley M. R (2005). Biofortifying crops with essential mineral elements. Trends Plant Science 10: 586-593.

[2] Bishai D. and Rita N. (2002). The History of Food Fortification in the United States: Its Relevance for Current Fortification Efforts in Developing Countries. Economic Development and Cultural Change. 51, 1 37-53.

[3] Campbell-Platt, G. (1994). Fermented foods- a world perspective. Food Research International 27: 253.

[4] Steinkraus K. H, (1996). Indigenous fermented foods involving an acid fermentation. Handbook of Indigenous Fermented Foods, Marcel Dekker, Inc. New York, 111-347.

[5] Sarwar, M. H., Sarwar, M. F., Sarwar, M., Quadri N. A. and Moghal S. (2013). The importance of cereals (Poaceae: Graminae) nutrition in human health: a review. Journal of cereals and oilseed. Vol. 4(3), 32-35. 
[6] Brigid McKevith, Nutritional aspects of cereals, (C) 2004 British Nutrition Foundation, Nutrition Bulletin 29, 111-142.

[7] M. Gobbetti and M. Gänzle (eds.), Handbook on Sourdough Biotechnology, 11 DOI 10.1007/978-1-4614-5425-0_2, (C) Springer Science + Business Media New York 2013.

[8] Odunfa, S. A. (1994). Development of starter cultures for nutritional enrichment of fermented cereals gruel. Journal of Applied Bacteriology 77:13-14.

[9] Ernst E. and Pittler M. H. (2001). Efficacy of ginger for nausea and vomiting: a systematic review of randomized clinical trials British Journal of Anesthesia 84(3): 367-371.

[10] AOAC, (2000): Official Methods of Analysis, 12th Ed. Association of Official Analytical Chemist. Washington, D. C. $112-117$.

[11] Fukushima D. (1999) Recent progress of soybean protein foods. Chemistry Technology and Nutrition Food Review International 7(3): $323-352$.
[12] Latona D. F., Oyeleke G. O., And Olayiwola O. A. (2012). chemical analysis of ginger root. 2278- 5736, 47-49.

[13] Mario K., Ton B., and Stephan G. (2012). "The relationship between high-fat dairy consumption and obesity, cardiovascular, and metabolic disease" DOI 10.1007/s00394012-0418-1.

[14] Duke J. A. (1981) Handbook of Legumes of Economic Importance. Plenum publishing cooperation New York 221 228.

[15] Kwanashie J. A., Elegbede A. A., Shuittu I. I., Onaja and Omagie J. J (1992). Studies on the formulation performance of a local laboratory animal feed. Journal of animal production research, 12: 55-68. 